\title{
CEsifo \\ WORKING

\section{Strategic Bidding of Electric Power Generating Companies: Evidence from the Australian National Energy Market}

Mardi Dungey, Ali Ghahremanlou, Ngo Van Long 


\section{Impressum:}

CESifo Working Papers

ISSN 2364-1428 (electronic version)

Publisher and distributor: Munich Society for the Promotion of Economic Research - CESifo $\mathrm{GmbH}$

The international platform of Ludwigs-Maximilians University's Center for Economic Studies and the ifo Institute

Poschingerstr. 5, 81679 Munich, Germany

Telephone +49 (o)89 2180-2740, Telefax +49 (o)89 2180-17845, email office@cesifo.de

Editors: Clemens Fuest, Oliver Falck, Jasmin Gröschl

www.cesifo-group.org/wp

An electronic version of the paper may be downloaded

- from the SSRN website: $\quad$ www.SSRN.com

- from the RePEc website: $\quad$ www.RePEc.org

- from the CESifo website: www.CESifo-group.org/wp 


\title{
Strategic Bidding of Electric Power Generating Companies: Evidence from the Australian National Energy Market
}

\begin{abstract}
We extend existing theoretical frameworks describing electricity markets where each generator provides a Market Operator (MO) with a supply schedule in advance. The MO combines these with demand forecasts to produce equilibrium prices and instructs firms on their dispatch. We incorporate the possibility that generating firms may rebid (or revise) their supply schedule prior to dispatch - an important feature of markets in many countries which has not previously been included in theoretical models. We show that a dominant firm can gain substantially by manipulating its bids, and take advantage of the opportunity to submit rebids. In the Australian National Energy Market (NEM) where settlement prices are an average of six dispatch prices, it can, for example, withhold capacity at lower prices for the first bid in a period, creating a price hike, and then add capacity at lower prices to ensure dispatch. Using data from the Australian NEM we provide the first empirical evidence consistent with the hypothesized theoretical behaviour in the observed data.
\end{abstract}

JEL-Codes: Q410, D430, D230.

Keywords: electricity markets, Australia, rebidding.

Mardi Dungey*

Tasmanian School of Business and Economics, University of Tasmania

Hobart / Tasmania / Australia mardi.dungey@utas.edu.au
Ali Ghahremanlou

Tasmanian School of Business and Economics, University of Tasmania

Hobart / Tasmania / Australia

ali.ghahremanlou@utas.edu.au

\author{
Ngo Van Long \\ Department of Economics \\ McGill University \\ Canada - H3A 2T7 Montreal Québec \\ ngo.long@mcgill.ca
}

\footnotetext{
*corresponding author
}

November 2017 


\section{Introduction}

The operations of de-regulated markets for electricity have generated a number of interesting questions: Do electricity generators have a lot of market power? Do they exercise their market power by collusion, or by non-cooperative strategic bidding? To what extent do observed price hikes reflect strategic bidding behaviour of generators? Do late rebids exacerbate price hikes?

A number of papers have addressed some of these issues both at the theoretical and the empirical level. One must bear in mind, however, that different electricity markets operate in different institutional settings. This makes it difficult to make comparisons across markets and to offer a 'general' theory. Nevertheless, prominent researches on electricity pricing in deregulated markets in the past two decade seem to have reached the consensus that oligopoly theories, together with analyses of the data suggest that electricity generators have been able to exploit their market power.

However, the existing literature ignores the real-world feature that in many national or regional markets, generators can revise their bids and make strategic use of the opportunity to submit their rebids. For example, in Alberta and Ontario, Canada, generators are allowed to make rebids up to two hours before dispatch. ${ }^{1}$ In Texas, bids may be changed up until one hour prior to the operation hour. ${ }^{2}$ In the Australian National Electricity Market (NEM), the more than 300 generators can rebid up to five minutes before dispatch. ${ }^{3}$ In this paper, we make specific references to the institutional setting of the NEM. Electricity-generating firms in the NEM are invited to submit, on date $t-1$, their bids (i.e., their supply schedules) for each of the 48 half-hour intervals for date $t$. Using these bids, the Market Operator (MO) provides forecast of the equilibrium prices, called 'pre-dispatch prices' (for each of the 48 half-hourly trading intervals, and under several different demand scenarios). Generators are allowed to revise their bids (supply schedules) up to 5 minutes before dispatch. Some interesting questions arise. Even if costs conditions do not change, will generators find it optimal to rebid in the light of the predispatch prices? Does the opportunity to rebid give generators an incentive to make misleading bids? ${ }^{4}$

Electricity generating companies have been modelled as Cournot rivals, Borenstein et al. (2002), as one-shot oligopolists which adopt static Nash behavior and do not try to collude (as in Klemperer and Meyer (1989)) and subject to capacity constraints (Green and Newbery (1992)). Using the Cournot model, Borenstein et al. found that 59 percent of the quadrupling in Californian wholesale electricity expenditure between 1998 and 2002 can be attributed to market power. ${ }^{5}$

\footnotetext{
${ }^{1}$ See Appendix E of Australian Energy Regulator (2015) for an international comparison of rules relating to rebids.

${ }^{2}$ Hortaçsu and Puller (2008),p.89 mentioned this feature of the Texan market, but they did n ot analyse how firms might strategically make use of the rebidding opportunity.

${ }^{3}$ The Australian set-up is similar to the bidding and re-bidding process in Ontario, Canada, and in New Zealand. In Ontario, a pre-dispatch schedule is published at 11:00 a.m. the day before dispatch. Suppliers are allowed to make re-bids up to 2 hours before dispatch.

${ }^{4}$ Chester (2006) mentioned a number of papers that argue that rebidding exposes the NEM to electricitygenerating companies with significant market power. Handika et al. (2014) studied price spikes in the Australian electricity market, but they did not address the issue of strategic behaviour.

${ }^{5}$ The Californian market is quite complex because there are two primary institutions, the Power Exchange (PX), and the Independent System Operator (ISO), which determine respectively the date-ahead market and the real-time electricity spot market. Firms could change their date-ahead positions by transacting in the spot
} 
Sweeting (2007) also found significant market power in the England and Wales wholesale electricity market, known as the Pool, for the period 1995-2000. Complementing this analysis with an alternative approach, using data on generators' bids and cost, he found that the two largest generators, National Power (NP) and PowerGen (PG), significantly deviated from the static noncooperative behavior, and concluded that 'their behaviour was consistent with tacit collusion' (p. 654). ${ }^{6}$

The literature on supply function equilibrium (SFEs) begins with the work of Klemperer and Meyer (1989) for an oligopoly facing a stochastic demand curve. Klemperer and Meyer (1989) study Nash equilibrium when firms' strategies are 'supply schedules' and find that there are many possible equilibria. The non-uniqueness of outcomes makes predictions problematic. Adapting SFE theory to the electricity spot market Green and Newbery (1992) ${ }^{7}$ find that there is a multiplicity of SFEs, but they arague that amongst these equilibria, the equilibrium that yields the maximum profit for each firm is the focal point SFE. Using this focal point as a prediction of firms' bids, Green and Newbery (1992) calibrate the model and calculate the potential deadweight loss for consumers. They find that the results are 'extremely disturbing' (p. 946) in terms of welfare loss.

The Klemperer and Meyer (1989) framework assumes that each firm knows everything about their rivals. However, Hortaçsu and Puller (2008) point out that in the Texas spot market, bidders are bound by (previously signed) bilateral agreements with their customers in the wholesale market, agreements that are unobserved by rivals. such obligations surely affect their bids in the real-time spot market. These bilateral contracts, which account for a substantial fraction of the power supply, are private information. Thus, Hortaçsu and Puller (2008) argue that one should look for a Bayesian-Nash equilibrium characterization of the bidding game, using the formulation proposed by Wilson (1979), Wilson (2002). Using data on bidders' marginal cost functions, they calculate an ex-post optimal supply schedule, which is an equilibrium bid function under the assumption that bid functions are additively separable in the private information possessed by bidders. Comparing he ex-post optimal bid schedules with the actual bids, they find that large Texan firms actual bids are close to the profit-maximising bids, but small Texan firms use excessively steep schedules, indicating deviation from profit maximisation. ${ }^{8}$

The purpose of this paper is to explore the strategic implications of the opportunity to make rebids, and analyze the rebidding data of the NEM to understand the significance of rebidding, given the institutional set up of the NEM.

Section 2 outlines the working of the Australian wholesale electricity market. In Section 3, we review some major existing theoretical models on bidding in the electricity market, with emphasis on supply function equilibria under non-cooperation. In section 4, we turn to collusive behavior, and develop a model of collusive bidding, assuming firms offer linear affine supply schedules. We

market.

${ }^{6}$ Sweeting (2007) notes that 'a complication is that generators signed unobserved quantities of financial contracts which hedged their exposure to pool prices'(p. 656).

${ }^{7}$ Green and Newbery (1992) add a capacity constraint for each firm, and reinterpreting the random variable in the K\&M model as time (since electricity demand varies with time).

${ }^{8}$ Hortaçsu and Puller (2008) argue that perhaps it is too costly for small firms to calculate the optimal mark-up (p.106). 
explore incentives for collusive firms to misreport their costs to the Market Operator, and also how they might signal their costs to each other.

In section 5, we turn to the non-collusive case with a dominant generator and a fringe of competitive generators, and show how the dominant firm may gain by taking advantage of rebids. We provide a simple example showing that a dominant generator can gain substantially in a 30-minute trading interval by manipulating its bid, and taqking advantage of the opportunity to submit rebids. It can, for example, withhold capacity for the first bid, creating price hike in the first 5-minute dispatch intervale, and then bring back its capacity in the following rebid which applies to the five remaining 5 -minute dispatch intervals.

Finally, in Section 6, we present data from the NEM drawn from the tens of millions of rebids tendered to the Australian Energy Market Operator (AEMO) over the period 2015 to 2017, which is suggestive of the supply-curve behavior of Australian electricity generators. We show that the observed behavior is consistent with our theoretical framework, with rebidding occurring in a strategically profitable manner across alternative generation methods and geographic locations. To our knowledge, this is the first empirical evidence of strategic rebidding extracted from a population of electricity generation data anywhere in the world. ${ }^{9}$

\section{The Australian National Electricity Market}

The Australian National Electricity Market (NEM), which began operation in December 1998, is a gross pool market for electricity, involving generators, electricity retailers, and large consumers, called 'scheduled loads'. Generators are required to make bids (i.e., to offer a supply schedule) and scheduled loads can also make demand-side bids. Both can make rebids. As pointed out in a document issued by Australian Energy Market Operator (2017), p.2, the NEM is an 'energy-only market' in the sense that generators are only compensated for the energy they supply to the central pool. ${ }^{10}$ The NEM encompasses five Australian states: Queensland, New South Wales, Victoria, South Australia and Tasmania. The state markets are connected by interstate 'imports' and 'exports' via a limited number of interconnectors. Spot prices differ across states, because of inter-regional transmission-capacity constraints which limit the scope for arbitrage. For example, Queensland is connected to other parts of the NEM only via two transmission lines to New South Wales, and only a single undersea interconnector links the Victorian and the Tasmanian electricity grids. This section gives an overview of the bidding rules, the determination of the spot price, and a brief account of the possibility of price manipulation. ${ }^{11}$

\subsection{Rules on bidding and rebidding}

Generators submit supply bids (and rebids) to the Australian Energy Market Operator (AEMO), who determines for each 5-minute interval a price, called the 'dispatch price' (to be distinguished

\footnotetext{
${ }^{9}$ This paper does not review approaches to forecasting electricity prices. (See Weron, 2014, for a comprehensive review of the literature on forecasting electricity prices.)

${ }^{10}$ This is in contrast to an energy-and-capacity market (e.g. Western Australia, which does not belong to the NEM) where suppliers also receive payments for their presence.

${ }^{11}$ Note that we focus on the spot market. There are hedge contracts between generators and retailers, but an examination of this issue is beyond the scope of this paper.
} 
from 'pre-dispatch prices' which are issued before the final rebids come in). Dispatch is the process whereby the Market Operator determines which generators should operate to meet the five-minute expected demand for electricity. The dispatch price is the bid of the most expensive generator that needs to be called on in order to equate supply to demand. ${ }^{12}$ Dispatch prices are not prices at which accounts are settled. Instead, generators are paid the 'settlement price' (also called 'spot price'), which is calculated for each half-hourly interval. It is an average of the six five-minute dispatch prices during that interval. For example, if the dispatch prices for 9:05am, 9:10am, 9:15 am etc., are denoted by $D_{1}, D_{2}, D_{3}$ etc., the settlement price for 9:30am is $P=\left(D_{1}+D_{2}+D_{4}+D_{5}+D_{6}\right) / 6$. This means that if a generator can manufacture a hike in the dispatch price of the last five-minute interval it will be able to increase the revenue for its previous dispatch outcomes within the 30 minute trading interval. ${ }^{13}$ In September 2017, the AEMC Australian Energy Market Commission (2017) issued a draft policy to change this rule to 5-minute settlement, with technical details in Australian Energy Market Operator (2017). As yet there are many technical difficulties to be resolved, and the earliest implementation of the change is likely to be 2021 .

In the prevailing NEM structure (since 1998) each electricity trading day $t$ commences at 4:00am on that day and ends at 3:59am on the following day. For each electricity trading day, bids are due before 12:30pm on the day prior (but rebids are allowed up to five minutes before each 5minute dispatch interval). The trading day is divided into 48 periods (each lasting 30 minutes). By 12:30pm on date $t-1$, electricity generating companies must submit their bids for all 48 half-hourly periods of the trading date $t$. Each bid must specify up to 10 price bands and 10 corresponding quantities (capacity increments) that the firm commits to supply. The nominated prices can be anywhere between the floor price of $-\$ 1000$ per MWh and the market price ceiling (MPC) imposed by regulation. ${ }^{14}$ Below is a stylised example of a bid. Negative prices reflect the costs which generators face in shutting off production at short notice. ${ }^{15}$

$$
\left[\begin{array}{ccccccccccc}
\text { band } & 1 & 2 & 3 & 4 & 5 & 6 & 7 & 8 & 9 & 10 \\
\text { price }(\text { \$per MWh }) & -999 & -45 & 2 & 8 & 20 & 25 & 35 & 60 & 220 & 400 \\
\text { qty } & 0 & 50 & 0 & 0 & 60 & 40 & 0 & 0 & 0 & 0
\end{array}\right]
$$

This schedule shows the cumulative amounts the generator is willing to dispatch; up to 150 units if the dispatch price is $\$ 25$ per MWh (or higher).

After receiving the bids, the Market Operator uses an algorithm to determine how forecast demand (for each of the 48 half-hourly periods) can be satisfied in the least costly way. This algorithm generates an estimated price, called "pre-dispatch price," for each of the 48 periods in date $t$, which we denote by $P_{t, \tau}^{e}$ for $\tau=1,2, . .48$. and a set of pre-dispatch bounds $P_{t, \tau}^{+\Delta}$ and $P_{t, \tau}^{-\Delta}$ for higher or lower demand outcomes ( $\left.\pm 200 \mathrm{MWh}\right)$. Four-hour ahead and twelve-

\footnotetext{
${ }^{12}$ Dispatch prices (every five minutes) are available on the website of AEMO, which also provides half-hourly spot prices.

${ }^{13}$ Demand-side responses by electricity retailers and large customers include switching on fast-response generators. The incentives to invest in short-duration demand response systems are limited because of the time-weighted 30 minute pricing.

${ }^{14} \mathrm{MPC}$ vary, but can be as high as $\$ 14,000$ per MWh.

${ }^{15}$ Coal-fired generators have very long start-up and shut-down times. It is better for them to stay online and face low or negative market prices for a number of trading intervals. Some coal-fired plants need a start-up time of three days or more (Australian Energy Market Commission, 2015, p. 16).
} 
hour ahead forecasts of demand, spot price, and available capacity are made available to market participants.

Generators use the information in pre-dispatch prices, and other up-dated informations (weather, repairs), to submit rebids. In submitting rebids, they are not allowed to change the 10 prices that they initially specified in their bids; their rebids are restricted to changes in the quantities to be made available at each price band. ${ }^{16}$ While offers apply to a whole 30-minute trading interval, rebids can be made during the trading interval and these affect the remaining 5 -minute dispatch interval(s). Generators can shift the quantities offered between the different price bands in response to changing market conditions. All rebids must be accompanied by an explanation. ${ }^{17}$ Generators can submit rebids up to five minutes before the actual dispatch. A rebid that shifts capacity from a lower price band to a higher price band has the effect of shifting the supply curve upwards, thus raising the price. ${ }^{18}$

Chester (2006, p. 364) gives the following illustrative example of re-bidding by a 600 MW generating unit. The original bid is

$\left[\begin{array}{cccccc}\text { band } & 1 & 2 & 3 & 4 & 5 \\ \text { price } & -20 & 25 & 55 & 90 & 120 \\ \text { qty } & 100 & 200 & 100 & 75 & 125\end{array}\right]$

and the rebid is

$\left[\begin{array}{cccccc}\text { band } & 1 & 2 & 3 & 4 & 5 \\ \text { price } & -20 & 25 & 55 & 90 & 120 \\ \text { qty } & 0 & 0 & 50 & 0 & 125\end{array}\right]$

The third row entries have changed but the entries in the first and second rows must remain unchanged. Diagrammatically, this means that the generating unit is allowed to re-draw its step-like supply schedule, keeping the height of each step unchanged, but the width of each step can shrink to zero, or can widen.

Chester (2006, p. 365) reports that "at least $40 \%$ of re-bids are made within one and a half hours of dispatch and at least $50 \%$ of re-bids have moved the volume of generation capacity from the original bid price-band to another price-band". For the year ending March 2001, in about $50 \%$ of cases, technical plant reasons were cited. Other reasons cited include 'market conditions', 'portfolio adjustment' and 'financial optimisation' Chester (2006, p. 366). ${ }^{19}$ Whenever spot price exceeds $\$ 5000 / M W h$, the Australian Market Regulator (AMR) is required to publish a report

\footnotetext{
${ }^{16}$ A similar restriction holds in the England and Wales market (Wolak (2000)): generators cannot change the price bid for each increment for the entire day, but they can vary the amount they are willing to supply from that capacity increment on a half-hourly basis.

${ }^{17}$ The rules have been tightened (Australian Energy Market Commission, 2015, p. xi). Effective from 1 July 2016, if a rebid is made during a 30-minute trading interval or less than 15 minutes before the commencement of the trading interval, the generator must make a contemporaneous record setting out the 1material conditions and circumstances' giving rise to the rebid. The record must be made available to the Australian Energy Regulator (AER) upon request. In the Federal Court case 'AER v. Stanwell', Justice Dowsett dismissed AER's application. He found that a trader's subjective expectations could be part of the material conditions and circumstances upon which a rebid could be based. (Australian Energy Market Commission, 2015, p. 111).

${ }^{18}$ The frequency at which capacity was shifted to price bands above $\$ 300$ per MWh was higher in Queensland than in other regions of the NEM; see Australian Energy Market Commission (2015, p. 83). Note that any price above $\$ 100$ per MWh is considered abnormally high, see Hurn et al. (2016, p. 712).

${ }^{19}$ Clements et al. (2016) examined strategic bidding and rebidding in the Queensland region of the NEM. In particular, they presented agregative evidence suggestive of rebidding after the extreme price spike on 28 August 2013.
} 
covering the circumstances relating to the price hike, including an assessment as to whether rebidding contributed to the event. ${ }^{20}$ There have been concerns that generators may deliberately delay their rebids to withhold information. More recent reports, prepared by ROAM Consulting and Oakley Greenwood for AEMC, suggest that since 2007, there has been an increasing trend for late rebids and some evidence of more rebids toward the end of the 30-minute trading intervals, particularly in Queensland and to some extent in South Australia ${ }^{21}$, and even more recently see Australian Energy Market Operator (2017).

\subsection{Price manipulation in Queensland}

A study by ROAM Consulting (Australian Energy Market Commission, 2015, p. 80-87) found that the tendency to make late rebids (i.e. close to dispatch time) is greater in Queensland than in any other region of the NEM. Price spikes above $\$ 300$ per MWh in Queensland during 2014 were found to be more frequent in the last 5-minute dispatch interval of the 30-minute trading interval (though this was not the case in 2007-2011). There was a positive correlation between price spikes and the number of late rebids moving capacity to high price bands. The likelihood of late rebids that move capacity into high price bands increases the incidence of binding transmission constraints and decreases in the spare capacity for interconnectors to import energy.

Empirically, Hurn et al. (2016) credits extreme price events in Queensland to "strategic behavior on the part of the generators" (p. 711). While their paper does not offer a formal theory of strategic bidding, it provides some explanation of how prices can be manipulated. In Queensland, the base-load generators are mainly coal-fired. They have low marginal costs but high cost of starting up and cooling down. In contrast, higher marginal cost gas-fired turbines are used mainly in peak periods. Hurn et al. (2016, p. 710) suggest that a base-load generator can influence the price by reducing to zero the width of lower steps of its supply schedule, i.e. by withholding capacity at the lowest price bands. ${ }^{22}$ This has the effect of shifting its supply schedule upward, forcing the market operator to raise the dispatch price. Once this is done, the base-load generator can rebid all its available capacity in the next and subsequent 5-minute intervals at the floor price to ensure it will be instructed to dispatch more, knowing that it gets paid not the floor price but the half-hour settlement price (which has been jacked up by the increase in the five-minute dispatch prices). Since the generator was not shut down, it does not take much time to ramp up to meet the instruction to increase the dispatch, giving these generators a strategic advantage. Even in the case where the manufactured price hike lasts only five minutes, the base-load generating units still gain because the price hike is translated into a higher spot price for the half-hour interval. When price hikes are of sufficiently short duration, peaking capacity

\footnotetext{
${ }^{20}$ For instance, on 1 June 2009 , the spot market price in Tasmania reached $\$ 9159 / M W h$ for the 30-minute trading interval ending at 10:00am, while the forecast spot price, announced 4 hours earlier, was $\$ 59 / M W h$. This price hike was due to Hydro Tasmanian shifting about $1000 \mathrm{MW}$ of capacity from prices below $\$ 300 / M W h$ to prices above $\$ 9000 / M W h$. The rebid was made about 90 minutes before dispatch. The reason given for the rebid was 'portfolio optimization.'

${ }^{21}$ Australian Energy Market Commission (2015), "Bidding in Good Faith. Final Rule Determination", 10 December 2015, page (v) and pages 82-87.

${ }^{22}$ This can be done either by declaring that the capacity is no longer available, or by shifting that capacity to a very high price band, say more than $\$ 300$ per MWh, as ROAM Consulting suggested (Australian Energy Market Commission, 2015, p. 83).
} 
operators, such as gas-fired turbines, cannot participate because the increase in the settlement price is not sufficient to cover their high marginal costs.)

The empirical strategy employed by Hurn et al. (2016) relies on the intuition that isolated halfhour high price events are more likely to be due to strategic behavior than those which continue for an hour or more (that is two or more consecutive settlement periods). They use this classification to determine whether there has been a change in the probability of observing abnormal price episodes after deregulation in July 2007. After July 2007, 44\% of price episodes lasted for half an hour, while before July 2007, the corresponding number was $39 \%$. The authors find that there is a significant increase in the probability of observing isolated half-hourly abnormal price episodes after the transition to the competitive market.

\section{The theory of supply function equilibrium: non-collusive bid- ding}

The pioneering theory of supply function equilibria by Klemperer and Meyer (1989) considers the case where oligopolistic firms commit to supply to the market specific quantities at specific market prices. ${ }^{23}$ Each of these firms announces a supply schedule, taking as given the supply schedules offered by other firms. Since there are just a few firms, these supply schedules are strategically chosen and do not correspond to marginal cost curves. Equilibrium price is where the market demand curve intersects the horizontal sum of the strategically chosen supply schedules. Klemperer and Meyer (1989) postulate that firms must announce their supply schedules before knowing the realization of a random variable that affects the demand curve. Several subsequent authors find that this theory is most suited to the study of deregulated markets for electricity (Bolle, 1992; Green and Newbery, 1992; Newbery, 1998) .

\subsection{Supply function equilibrium with smooth supply schedules}

Each of the $n$ firms (electricity generators) must submit a bid, which takes the form of a schedule $q_{i}(p)$. For each spot price $p$, the firm is committed to supply a corresponding quantity, denoted by $q_{i}(p)$. For simplicity, for the moment we assume that $p$ is a real number that can take any value in $[0, \infty)$, and assume that $q_{i}(p)$ is a smooth function. ${ }^{24}$ The quantity demanded depends on two variables, $p$ and $a$, where $p$ is the spot price, and $a$ is a random term (or, in a different interpretation of the model, $a$ refers to time of the day, suitably re-ordered, so that $D_{a}>0$. $)^{25}$

$$
Q^{d}=D(p, a)
$$

Assume that $D_{p}<0$ and $D_{a}>0$. A simple specification is $D(a, p)=a-b p$, i.e., the 'random term' $a$ influences only the vertical intercept of the demand curve. We shall refer to any realization $a$ as 'the state of the world', or simply 'state' $a$.

\footnotetext{
${ }^{23}$ In other words, they are neither Cournot players, which commit to quantities, nor Bertrand players, which commit to prices.

${ }^{24}$ An alternative formulation would be to require that $q(p)$ be a step-like supply function (von der Fehr and Harbord, 1993). These authors show that with this formulation, in general there is no equilibrium in pure strategies. Repeated auctions are difficult to solved when there is no pure strategy equilibrium.

${ }^{25}$ See Green and Newbery (1992), and Newbery (1998), footnote 12.
} 
The firms must submit their supply schedules, and commit to them, before the 'random variable' $a$ is realized. The market operator (MO) then determines, for each $a$, the equilibrium price $p(a)$ that clears the market, i.e., $p(a)$ is the implicit function determined by the market-clearing condition

$$
D(p, a)=\sum_{i=1}^{n} q_{i}(p)
$$

For a given realization of $a$, firms are required to supply the quantities $q_{i}(p(a))$, and are paid the amount $p(a) \times q_{i}(p(a))$. Firm $i$ 's realized profit in 'state' $a$ is then

$$
\pi_{i}(a)=p(a) \times q_{i}(p(a))-C_{i}\left[q_{i}(p(a))\right]
$$

where $C_{i}($.$) is the total cost function.$

Suppose firm $i$ knows the supply functions of all other firms $j \neq i$. Then it knows that at any $a$, it faces the 'residual demand function'26

$$
R_{i}(p, a) \equiv D(p, a)-S_{-i}(p)
$$

where $S_{-i}(p)$ is the aggregate quantity supplied by all other firms at the price $p$ :

$$
S_{-i}(p) \equiv \sum_{j \neq i} q_{j}(p)
$$

Then, in 'state' $a$, firm $i$ 's profit given that it must produce to satisfy the residual demand is

$$
\Pi_{i}(p, a) \equiv p \times R_{i}(p, a)-C_{i}\left[R_{i}(p, a)\right]
$$

As Klemperer and Meyer pointed out, firm i's optimal (i.e. best response) supply function can be solved by positing that it is as if the firm would choose a price $p$ (corresponding to each $a$ ) to maximize the profit $\Pi_{i}(p, a)$ for each realization of $a$. The first order condition (FOC) is ${ }^{27}$

$$
R_{i}(p, a)+p \frac{\partial R_{i}(p, a)}{\partial p}-C_{i}^{\prime}\left[R_{i}(p, a)\right] \frac{\partial R_{i}(p, a)}{\partial p}=0
$$

This equation determines the profit-maximizing price for the firm at a given $a$.

If $\Pi_{i}(p, a)$ is strictly concave in $p$, then the FOC determines a unique price $p_{i}^{*}(a) \equiv f(a)$ that firm $i$ would want to achieve for each value of $a$. At that price, the quantity supplied by $i$ is

$$
q_{i}^{*}(a) \equiv R_{i}\left(p_{i}^{*}(a), a\right)
$$

If the function $p_{i}^{*}(a) \equiv f(a)$ is invertible, ${ }^{28}$ then we can solve for firm $i$ 's optimal (i.e. best reply) supply function $q_{i}=S_{i}(p)$ :

$$
q_{i}=S_{i}(p)=q_{i}^{*}\left(f^{-1}(p)\right)
$$

\footnotetext{
${ }^{26}$ Firm $i$ 's "residual demand curve" shows, at any price $p$, the difference between industry demand and the sum of quantities that all other firms are willing to supply at that price.

${ }^{27}$ The second order condition is satisfied if $R_{i}$ is concave in $p$ and $C_{i}\left(q_{i}\right)$ is a convex function.

${ }^{28}$ Given that $D_{a}<0$ and $C^{\prime \prime} \geq 0$, a sufficient condition for the invertibility of $f($.$) is that D_{p a}=0$ identically, as this ensures that $\Pi_{p a}$ does not change sign.
} 
EXAMPLE 1: Assume that firm $i$ 's cost function is

$$
C_{i}\left(q_{i}\right)=\frac{1}{2} \gamma_{i} q_{i}^{2}
$$

Let the demand function be

$$
D(p, a)=a-b p
$$

and assume that the (aggregate) supply function of other firms is

$$
S_{-i}(p)=\beta p, \text { where } \beta \geq 0 .
$$

Then the residual demand function facing firm $i$ is

$$
R_{i}(p, a)=a-(b+\beta) p
$$

The FOC (1) gives

$$
[a-(b+\beta) p]-\left[p-\gamma_{i}(a-(b+\beta) p)\right](b+\beta)=0
$$

This yields

$$
p_{i}^{*}(a)=\frac{a\left[1+\gamma_{i}(b+\beta)\right]}{(b+\beta)\left[2+\gamma_{i}(b+\beta)\right]}
$$

and

$$
q_{i}^{*}(a)=a-(b+\beta) p_{i}^{*}(a)
$$

The function $p_{i}^{*}(a)$, also denoted by $f(a)$, can be inverted to yield $a=f^{-1}(p)$

$$
a=\frac{(b+\beta)\left[2+\gamma_{i}(b+\beta)\right]}{1+\gamma_{i}(b+\beta)} p_{i}^{*}
$$

Then we obtain firm $i$ 's optimal supply function by substituting for $a$ in equation (2)

$$
\begin{aligned}
q_{i} & =\frac{(b+\beta)\left[2+\gamma_{i}(b+\beta)\right]}{1+\gamma_{i}(b+\beta)} p-(b+\beta) p \\
& =\frac{(b+\beta) p}{1+\gamma_{i}(b+\beta)} \equiv \omega p
\end{aligned}
$$

In this example, using the assumption that the random variable $a$ can take on any value in the half line $[0, \infty)$, we have shown that, given that other firms' supply functions (i.e., "strategies") are linear in $p$, firm $i$ 's "best response" is a linear supply function. If there are only two firms, and $\gamma_{1}=\gamma_{2}$, we must have $\beta=\omega$, and thus obtain a unique symmetric SFE in linear strategies:

$$
q_{i}=\frac{1}{2}\left[-b+\sqrt{b^{2}+\frac{4 b}{\gamma}}\right] p, i=1,2
$$

As Klemperer and Meyer (1989) point out, this result does not rule out the possibilities that there exists SFEs in which firms bid non-linear supply functions for some range of $p$ (see Klemperer and Meyer, p. 1260). 


\subsection{SFE when the random variable is bounded above}

Green and Newbery (1992) do not think that it is realistic to allow the variable $a$ to take on arbitrarily large values. Assuming an upper bound on $a$ (i.e. $a \leq a_{\max }$ ) and constant marginal cost, Newbery (1998, p. 732) considers the two-firm case, and shows that SFE can be found by solving the following differential equation ${ }^{29}$

$$
\frac{d q}{d p}=\frac{q}{p-C^{\prime}(q)}+D_{p}
$$

Assuming $D_{p}=-b<0$, and $C^{\prime}(q)=0$, Newbery (1998, p. 732) shows that in equilibrium the supply function of each firm takes the form

$$
q(p)=A p-b p \ln p, \text { for } 0<p<\frac{a_{\max }}{3 b} .
$$

where $A$ is a constant of integration. It follows that there is a continuum of SFEs, each corresponding to a value of the constant of integration $A .^{30}$

Newbery (1998) generalises the supply function equilibrium to the case of $n$ identical firms with constant marginal cost, under linear demand with bounded vertical intercept. He shows that the more firms there are, the lower is the highest aggregate supply schedule. ${ }^{31}$

\subsection{The step-like supply functions}

In the real world, each generating company typically operates several generating units (or 'sets') and offers step-supply schedules. In an innovative paper, von der Fehr and Harbord (1993) argue that if sets are of significant size, the results obtained under the assumption of smooth supply functions may not hold. Their alternative model suggests that 'high-cost sets may be bid in at lower offer prices than lower-cost sets' (p. 532).

Consider the model of von der Fehr and Harbord (1993), which belongs to the literature on multiple-unit auctions. ${ }^{32}$ There are $N$ generating companies, indexed by $g=1,2, \ldots, N$. Assume that generating company $g$ has $m_{g}$ generating units (or 'sets'). Let $k_{g s}$ denote the capacity of the $s$-th set of generating company $g$. Define the capacity of the generating company $g$ by

$$
k_{g}=\sum_{s=1}^{m_{g}} k_{g s} .
$$

The capacity of the industry is

$$
K=\sum_{g=1}^{N} k_{g} .
$$

\footnotetext{
${ }^{29}$ See Appendix A for the derivation of this equation.

${ }^{30}$ Newbery shows that any value of $A$ in the interval $\left(0, b\left(1-\ln \left(3 b / a_{\max }\right)\right]\right.$ defines a pair of equilibrium supply schedule for some range of $p$.

${ }^{31}$ Another complication is capacity constraint. Klemperer and Mayer assume that firms do not face any capacity constraints. Green and Newbery (1992) add realism to the SFE approach by imposing capacity constraints.

${ }^{32}$ McAfee and McMillan (1987, p. 724-5) provide a brief review of this literature.Kastl (2011) offers a more general treatment of the theory of discrete bids and discusses the empirical inference in this context. With discrete bids, a firm's residual demand function is a step function. However, Hortaçsu and Puller (2008) found that in practice the calculations of ex-post profitability under the "unsmoothed" residual demand do not differ much from the ex-post profitability under the the "smoothed" residual demand.
} 
With perfectly inelastic demand, regardless of the price, the quantity demanded is $d$, which is a random variable with distribution $G(d)$. Each generator $g$ submits bid prices $p_{g s}$ for $s=$ $1,2, \ldots, m_{g}$. Assume that the bids are not allowed to be higher than an exogenous ceiling price $\bar{p}$. The market operator ranks the bids to obtain a market supply curve. Upon the realization of the random variable $d$, the spot price is determined by equating demand and supply. All operating units that actually supply a positive output receive the same spot price. ${ }^{33}$ If two sets have the same bid prices, they are equally likely to be called into operation.

von der Fehr and Harbord assume that each generating company $g$ has constant marginal cost $c_{g}$ for all its sets. By convention, the companies are labelled so that $c_{g+1} \geq c_{g}$. They point out that typically firms will play mixed strategies in equilibrium, because a firm that offers a fixed bid is likely to be undercut by other firms: with a block supply, the gain from undercutting can be substantial. (This is in sharp contrast to the case where each set is 'infinitesimally small'). The authors derive the mixed strategy equilibrium for the case of duopoly with $0=c_{1} \leq c_{2} \equiv c$, and for the case of $n$ generating companies with identical costs. ${ }^{34}$ They find that the expected spot price is decreasing in $N$. They conclude that "for a given number of generating sets in the industry, system marginal price will be a decreasing number of owners" (p. 537).

The theoretical model of von der Fehr and Harbord (1993) is not meant to be tested directly. The authors find that actual bidding behavior is consistent with the predictions of the model.

\subsection{Discriminatory versus uniform auctions}

Wholesale electricity markets are typically organized as uniform, first-price auctions. In March 2001 the UK introduced a discriminatory (pay-as-bid) auction format. Fabra et al. (2006, p. 23) report, 'The British regulatory authority (Ofgem) believed that uniform auctions are more subject to strategic manipulation by large traders than are discriminatory auctions.' However, they also point out (p. 24) that there are no consensus on the superiority of one form of auction over the other. $^{35}$

The two forms of auctions are compared in Fabra et al. (2006), but their main analysis is based on the special assumption that the firms observe the realization of demand before they submit their bids. (This assumption may be suitable for markets in which the price offers (bids) are short-lived, such as in Spain; it is not suitable for markets in which price offers must remain fixed for the whole day, e.g., in Australia.) ${ }^{36}$

\footnotetext{
${ }^{33}$ As pointed out by the authors, in the UK, in most half-hour periods (called Table A periods), each dispatched generating set (genset) is paid, in addition to the system marginal price, a capacity element which reflects the probability of loss of load (a power shortage).

${ }^{34}$ See their working paper version, 1992.

${ }^{35}$ Second-price auctions, first practised by the poet Goethe in 1797 (see Moldovanu and Tietzel (1998)) are common on the internet (e.g. ebay auctions), but have not been used for electricity bidding.

${ }^{36}$ Fabra et al. (2006) also briefly consider the case of 'long-lived bids' in which suppliers face time-varying demand, see p. 34-36. They are only able to characterize the mixed-strategy equilibria in the case each supplier has only one generating set, i.e., the step function has only one step.
} 


\section{Collusive bidding by heterogeneous oligopolists}

Let us turn to a simple model of collusive behavior. Assume that the industry consists of only two firms, denoted by $i=1,2 .{ }^{37}$ Their outputs are denoted by $q_{1}$ and $q_{2}$ respectively. Their combined output is $Q=q_{1}+q_{2}$. Assume that the firm $i$ 's true marginal cost is $\alpha_{i}+\beta_{i} q_{i}$, and its total cost is

$$
C_{i}\left(q_{i}\right)=\alpha_{i} q_{i}+\frac{\beta_{i}}{2}\left(q_{i}\right)^{2}
$$

The demand function is

$$
D(P)=\left\{\begin{array}{ll}
\frac{A-P}{B} & \text { if } P \leq A \\
0 & \text { if } P>A
\end{array} .\right.
$$

from which we obtain the demand curve $P(Q)$

$$
P(Q)=A-B Q
$$

We assume that the price intercept of the demand curve is higher than the intercept of the marginal cost schedules, $\mathrm{A}>\max \left(\alpha_{1}, \alpha_{2}\right)$.

\subsection{The benchmark scenario}

Assume for the moment that the firms have perfect knowledge of the parameters $A$ and $B$. If they collude, they will behave such that the industry marginal revenue equals the industry's marginal cost. For any desired industry output level $Q$, the collusive firms will choose $q_{1}$ and $q_{2}$ to minimize the production cost subject to $q_{1}+q_{2}=Q$. The cost-minimizing outputs for the collusive firms are

$$
\begin{aligned}
& q_{1}=\left(\frac{\beta_{2}}{\beta_{1}+\beta_{2}}\right) Q+\left(\frac{\alpha_{2}-\alpha_{1}}{\beta_{1}+\beta_{2}}\right) \equiv q_{1}(Q) \\
& q_{2}=\left(\frac{\beta_{1}}{\beta_{1}+\beta_{2}}\right) Q+\left(\frac{\alpha_{1}-\alpha_{2}}{\beta_{1}+\beta_{2}}\right) \equiv q_{2}(Q)
\end{aligned}
$$

For the collusive firms, their total cost of supplying the aggregate quantity is

$$
C(Q)=\alpha_{1} q_{1}(Q)+\frac{\beta_{1}}{2}\left(q_{1}(Q)\right)^{2}+\alpha_{2} q_{2}(Q)+\frac{\beta_{2}}{2}\left(q_{2}(Q)\right)^{2}
$$

The collusive firms equate marginal revenue with marginal cost to determine their collusive aggregate output:

$$
Q^{*}=\frac{A\left(\beta_{1}+\beta_{2}\right)-\left(\alpha_{1} \beta_{2}+\alpha_{2} \beta_{1}\right)}{\beta_{1} \beta_{2}+2 B\left(\beta_{1}+\beta_{2}\right)}
$$

The optimal outputs of the firms are $\operatorname{are}^{38}$

$$
q_{1}=\left(\frac{\beta_{2}}{\beta_{1}+\beta_{2}}\right)\left(\frac{A\left(\beta_{1}+\beta_{2}\right)-\left(\alpha_{1} \beta_{2}+\alpha_{2} \beta_{1}\right)}{\beta_{1} \beta_{2}+2 B\left(\beta_{1}+\beta_{2}\right)}\right)+\left(\frac{\alpha_{2}-\alpha_{1}}{\beta_{1}+\beta_{2}}\right)
$$

and

$$
q_{2}=\left(\frac{\beta_{1}}{\beta_{1}+\beta_{2}}\right)\left(\frac{A\left(\beta_{1}+\beta_{2}\right)-\left(\alpha_{1} \beta_{2}+\alpha_{2} \beta_{1}\right)}{\beta_{1} \beta_{2}+2 B\left(\beta_{1}+\beta_{2}\right)}\right)+\left(\frac{\alpha_{1}-\alpha_{2}}{\beta_{1}+\beta_{2}}\right)
$$

\footnotetext{
${ }^{37}$ Extension to the case of $n$ heterogeneous firms is straightforward.

${ }^{38}$ We assume that $\max \left\{\alpha_{1}-\alpha_{2}, \alpha_{2}-\alpha_{1}\right\}$ is small enough so that firms' outputs are positive.
} 


\subsection{Achieving the collusive output by coordinating supply functions}

Now, suppose that the collusive firms cannot directly set quantities nor price. Instead, they have to 'bid' by providing to the Market Operator their 'supply functions', and the latter will determine the price that equates demand to supply. What are the 'supply functions' that will achieve the highest profit for the collusive firms? Can the firms achieve the monopoly profit by bidding linear 'supply functions'?

Suppose the firms are required to offer supply functions (bids)

$$
q_{i}(P)=\frac{P-a_{i}}{b_{i}}
$$

The Market Operator then construct the aggregate supply scheduleS $(\mathrm{P})=q_{1}(\mathrm{P})+q_{2}(\mathrm{P})$, and for a given realization of $\mathrm{A}$, the firms' supply schedules must be such that $a_{1}, a_{2}, b_{1}$ and $b_{2}$ satisfy the conditions

$$
\begin{aligned}
& b_{1}=\beta_{1}+\frac{\left(\beta_{1}+\beta_{2}\right) B}{\beta_{2}} \\
& b_{2}=\beta_{2}+\frac{\left(\beta_{1}+\beta_{2}\right) B}{\beta_{1}} \\
& a_{1}=\alpha_{1}+\frac{\left(\alpha_{1}-\alpha_{2}\right) B}{\beta_{2}}
\end{aligned}
$$

and

$$
a_{2}=\alpha_{2}+\frac{\left(\alpha_{2}-\alpha_{1}\right) B}{\beta_{1}}
$$

Suppose $\beta_{1}=\beta_{2}=\beta$. Then their supply functions will have the slope

$$
b_{1}=b_{2}=\beta+2 B
$$

, i.e., both firms exaggerate the slope of their marginal cost curves. And the intercepts will be

$$
\begin{aligned}
& a_{1}=\alpha_{1}+\left(\alpha_{1}-\alpha_{2}\right) B / \beta \\
& a_{2}=\alpha_{2}+\left(\alpha_{2}-\alpha_{1}\right) B / \beta
\end{aligned}
$$

Thus the firm with the higher (lower) intercept will overstate (understate) its intercept.

\subsection{Sending signals}

In the preceding section, we assume that firms know each other's true marginal costs. Suppose that each firm $i$ knows its $\alpha_{i}$ and $\beta_{i}$ at the beginning of each day, but they cannot directly communicate this information to the other firm (perhaps because of anti-trust legislations). Then one way of communication would be to submit to the Market Operator (MO) the numbers $\left(a_{i}, b_{i}\right)$. The MO will then construct the supply curve, and announce the forecasted dispatch price, $P_{F}^{M O}$.(Here the subscript $F$ indicates that the price is only a forecast price, subject to 
change that the $\mathrm{MO}$ will make upon receiving the revised bids.) Upon receiving $P_{F}^{M O}$, firms will make some inferences about the true costs of the other firm. (We have to model a 'reasonable' inference process.) They will then revise their bids, with the objective of maximizing their joint profits.

Consider the simplest case, where the only random cost parameter is $\alpha_{1}$ (i.e., the other three parameters, $\alpha_{2}, \beta_{1}$ and $\beta_{2}$ are not random). Suppose that $\alpha_{1}$ is either high $\left(=\alpha_{1}^{H}\right)$ or low $\left(=\alpha_{1}^{L}\right)$. Suppose the firms are allowed to revise their bids only once. When firms make their first round bids, firm 1 already knows the realization of $\alpha_{1}$, but firm 2 does not. The latter supposes that $\alpha_{1}=\alpha_{1}^{H}$ with probability $p$ and $\alpha_{1}=\alpha_{1}^{L}$ with probability $1-p$. Let us suppose that the firm 2 makes its first round bid as if $\alpha_{1}=p \alpha_{1}^{H}+(1-p) \alpha_{1}^{L} \equiv E \alpha_{1}$. Then its 'reported' first-round linear supply function is

$$
q_{2}(P)=\frac{P-a_{2}}{b_{2}}
$$

where,

$$
a_{2}=\alpha_{2}+\left(\alpha_{2}-E \alpha_{1}\right) B / \beta
$$

and

$$
b_{2}=\beta+2 B
$$

Suppose that firm 1's first-round bid uses a similar rule, i.e., $b_{1}=\beta+2 B$ and, when the realized value of $\alpha_{1}$ is $\alpha_{1}^{H}$, its reported value is

$$
a_{1}^{H}=\alpha_{1}^{H}+\left(\alpha_{1}^{H}-\alpha_{2}\right) B / \beta
$$

while if $\alpha_{1}=\alpha_{1}^{L}$, then

$$
a_{1}^{L}=\alpha_{1}^{H}+\left(\alpha_{1}^{H}-\alpha_{2}\right) B / \beta
$$

If $a_{1}^{H}$ is reported, the market operator will calculate that the aggregate supply schedule, and announce the dispatch price that would equate demand and supply. Now comes round 2. At this stage, firm 2 , having observed $A$, and having received the price sent by the market operator, can infer (with certainty) whether firm 1 has reported $a_{1}^{L}$ or $a_{1}^{H}$. The round 2 bids will reflect the firms' perfect knowledge about $\alpha_{1}$.

\section{Strategic bid and rebid by a dominant firm}

In the preceding section, the focus was on collusive behavior of suppliers that are similar. In this section, we turn to the case of an industry consisting of a large dominant firm and a competitive fringe. We show that the dominant firm has a strong incentive to submit bids and rebids strategically in order to generate a price hike over a short time interval (say, half an hour).

The dominant firm can manufacture a price hike either toward the end of the 30 minute trading interval, or at the beginning of it. Let us illustrate both possibilities. 


\subsection{Manufacturing a price hike in the first dispatch interval}

Let us consider a simple numerical example. Assume that the electricity demand for each 5minute interval is $\bar{Q}=120 \mathrm{MW}$. There is a base-load generator (which we call the 'dominant firm') that has two generating sets with capacity of $42 \mathrm{MW}$ and $38 \mathrm{MW}$ respectively. Their corresponding marginal costs are $\$ 0$ per $\mathrm{MWh}$ and $\$ 5$ per $\mathrm{MWh}$. There are a large number of higher cost generators (which we call the 'fringe') that can collectively supply the first 40 units of capacity at the marginal cost of $\$ 15$ per MWh, a further 10 units of capacity with a marginal cost of $\$ 30$ per MWh, and another 10 units of capacity at a marginal cost of $\$ 80$ per MWh. Any further increase in output from the fringe would involve a marginal cost of $\$ 1000$ per MWh. ${ }^{39}$ Assume that if the dispatch price in the first five-minute interval turns out to be abnormally high, there will be some lagged demand-side response in the forms of self-supply: for example, retailers can switch on their own gas-fired turbines. We assume that such demand-side responses will take time: 10 units of capacity can be brought online for second five-minute interval, and 20 units at the third and each subsequent five-minute interval.

Suppose for the moment that all firms are truthful and bid according to their marginal costs. Then a truthful bid of the dominant generator will be, for example,

$$
\left[\begin{array}{ccccccccccc}
\text { band } & 1 & 2 & 3 & 4 & 5 & 6 & 7 & 8 & 9 & 10 \\
\text { price } & -999 & 0 & 5 & 15 & 30 & 80 & 100 & 500 & 800 & 1000 \\
\text { qty } & 0 & 42 & 38 & 0 & 0 & 0 & 0 & 0 & 0 & 0
\end{array}\right]
$$

and the fringe's bid will be

$$
\left[\begin{array}{ccccccccccc}
\text { band } & 1 & 2 & 3 & 4 & 5 & 6 & 7 & 8 & 9 & 10 \\
\text { price } & -999 & 0 & 5 & 15 & 30 & 80 & 100 & 500 & 800 & 1000 \\
\text { qty } & 0 & 0 & 0 & 40 & 20 & 10 & 0 & 0 & 0 & 10
\end{array}\right]
$$

To satisfy the demand of $120 \mathrm{MW}$, the MO will instruct to dominant firm to dispatch 80 $\mathrm{MW}$, and the fringe firms to dispatch $40 \mathrm{MW}$ for each of the five-minute intervals. Since 5 minutes amounts to $1 / 12$ of an hour, over the five minutes, the energy outputs they produce are respectively $80 \times(1 / 12) \mathrm{MWh}$ and $40 \times(1 / 12) \mathrm{MWh}$. The dispatch price is $\$ 15$ per MWh. It reflects the marginal cost of the fringe firms. For each 5 -minute interval the dominant firm will earn a profit of

$$
(15-0) \times 42 \times(1 / 12)+(15-5) \times 38 \times(1 / 12)=\$ 84.167
$$

Its profit for the 30 minute trading interval is $\$ 505$

Now consider a possible strategic move by the dominant firm. Just five minutes prior to the trading interval, it sumbits a rebid that offers to supply the 38 units of capacity from the second generating set only at the ceiling price of $\$ 14,000$ per $\mathrm{MWH}$, indicating that it would supply only 42 units of capacity from the first generating set if the price is positive but below $\$ 14,000$ per Mwh:

$$
\left[\begin{array}{ccccccccccc}
\text { band } & 1 & 2 & 3 & 4 & 5 & 6 & 7 & 8 & 9 & 10 \\
\text { price } & -999 & 0 & 5 & 15 & 30 & 80 & 100 & 500 & 800 & 1000 \\
\text { qty } & 0 & 42 & 0 & 0 & 0 & 0 & 0 & 0 & 0 & 0
\end{array}\right]
$$

\footnotetext{
${ }^{39}$ Bid prices in the vicinity of $\$ 14,000$ per MWh have been observed in Queensland, though the average price is below $\$ 80$ per MWh. See e.g. Hurn et al. (2016).
} 
Then, to satisfy the demand of $120 \mathrm{MW}$, the MO must set the dispatch price $D_{1}=\$ 1000$ for the first 5-minute interval. We assume that this very high dispatch price triggers a demandside response: the output from gas peaking generators owned by retailers will become available. Suppose 10 units of capacity will be available for second five-minute interval, and 20 units of capacity for the third and each subsequent five-minute interval. Consequently, the MO operator must satisfy a net demand of $110 \mathrm{MW}$ in the second 5-minute interval, and a net demand of 100 MW in each of the subsequent 5-minute intervals. The dispatch prices for these five-minutes intervals will be $D_{2}=\$ 80$ (since 110 units are dispatched, consisting of 42 units from the dominant generator and 68 units from the fringe), and $D_{3}=D_{4}=D_{5}=D_{6}=\$ 30$ (since 100 units are dispatched, consisting of 40 units from the dominant generator and 60 units from the fringe).

The 'settlement price' is the time-weighted average of the dispatch prices

$$
\begin{aligned}
P & =\left(D_{1}+D_{2}+D_{3}+D_{4}+D_{5}+D_{6}\right) / 6 \\
& =(1000+80+30+30+30+30) / 6 \\
& =\$ 200 \text { per MWh }
\end{aligned}
$$

At this settlement price, the profit of the dominant firm per five minute interval is

$$
200 \times 42 \times(1 / 12)=\$ 700
$$

Its profit for the 30 minute trading interval is

$$
700 \times 6=\$ 4,200
$$

This is much greater than the profit of $\$ 505$ that the firm would earn with an honest bid. Thus, it pays to withhold capacity from the second generating set for the whole 30 minute trading period.

However, we will show below that the dominant firm can do even better by rebidding (after the dispatch price peak of $\$ 1,000$ ), offering the $38 \mathrm{MW}$ capacity from the second generating set for the second and subsequent 5-minute intervals at the low price of $\$ 5$ per MWh. Effective from the second 5-minute interval,

$$
\left[\begin{array}{ccccccccccc}
\text { band } & 1 & 2 & 3 & 4 & 5 & 6 & 7 & 8 & 9 & 10 \\
\text { price } & -999 & 0 & 5 & 15 & 30 & 80 & 100 & 500 & 800 & 1000 \\
\text { qty } & 0 & 42 & 38 & 0 & 0 & 0 & 0 & 0 & 0 & 0
\end{array}\right]
$$

In the second 5-minute interval, the Market Operator must satisfy a net demand of 110 units (recall that, as a demand-side response, in the second 5-minute interval, the retailers can bring online 10 units of capacity, and $20 \mathrm{MW}$ capacity will be available during each subsequent 5minute interval). To satisfy this net demand, the MO will ask the dominant firm to dispatch 80 units and the fringe to dispatch 30 units. Since the fringe's marginal cost is $\$ 15$ per $\mathrm{MWh}$, the dispatch price for the second 5 -minute interval is $\$ 15$ per MWh.

In the third 5-minute interval, the Market Operator must satisfy a net demand of 100 units. This is done by asking the dominant firm to dispatch 80 units and the fringe to dispatch 20 
units. Again the dispatch price is $\$ 15$ per MWh. The settlement price is

$$
\begin{aligned}
P & =\left(D_{1}+D_{2}+D_{3}+D_{4}+D_{5}+D_{6}\right) / 6 \\
& =(1000+15+15+15+15+15) / 6 \\
& =\$ 179.17 \text { per MWh }
\end{aligned}
$$

The profit of the dominant firm in the first 5-minute interval is

$$
179.17 \times 42 \times(1 / 12)=\$ 627.10
$$

and its profit in each of the five subsequent 5-minute intervals is

$$
179.17 \times 42 \times(1 / 12)+(179.17-5) \times 38 \times(1 / 12)=\$ 1,178.60
$$

Its total profit for the 30 minute trading interval is

$$
627.10+5 \times(1178.60)=\$ 6,520.10
$$

This is much greater than the profit of $\$ 4,200$ that it would obtain if it did not rebid (i.e. if it continued to withhold 38 units of capacity for the last five 5-minute intervals).

\subsection{Manufacturing a price hike in the last dispatch interval}

In the preceding subsection, we assumed that a firm can withhold capacity for the first 5-minute dispatch interval to increase the first 5-minute dispatch price (and consequently the settlement price for the half-hour trading interval), and subsequently rebid the capacity for the second 5minute interval. In some cases, such behavior can be risky: the regulator may have have grounds to prosecute the firm. It may be safer to withhold capacity in the sixth 5-minute dispatch interval rather than in the first 5-minute dispatch interval. This will increase the dispatch price for the sixth 5-minute dispatch interval, and consequently raising the settlement price for the firm's five earlier dispatches. If the firm's competitors could anticipate the settlement price hike, they would increase their capacity offers, and it would not be worthwhile for the firm to withhold capacity. It is crucial, therefore, that the firm's withholding of capacity for the sixth 5-minute interval be made public as late as possible, so that the 'surprise price hike' gives the competitors little time to react.

\section{Rebidding in the Australian Electricity Market}

For a number of years the market operator has reported little evidence of rebidding activity. For example Australian Energy Market Commission (2015) engaged ROAM Consulting to undertake a quantitative analysis of rebidding in the NEM. ROAM's key findings for 2007-2014 were reported on page 80 of AEMC Australian Energy Market Commission (2015) with four relevant conclusions. First they found little evidence of a systematic tendency for rebidding toward the end of trading intervals or in rebidding just prior to dispatch, with the exception of recent episodes in Queensland and to some extent in South Australia. Second, a strong statistically 
significant relationship exists between the probability of price spikes and late rebidding in QLD in 2014 and SA in 2013. In QLD and SA the rebidding generally shifted capacity to high price bands, and in 2013 and 2014 QLD markets showed evidence of generation withholding capacity to high price bands towards the end of the trading intervals.

The evidence used to support the lack of systematic rebidding presented in Figure 8.2 of the Australian Energy Market Operator (2017) report strongly suggests that further investigation is necessary. First, the data provided take no account of potential diurnality or seasonality effects. By collating all 'last 5-minute dispatch' rebids for every settlement period into a single representation over a year, the graph masks time-of-day, day-of-week and seasonal patterns. Similarly, by aggregating the rebids across all generators the data masks the strategic behavior taken at both generator and potentially portfolio level, given that there are fewer electricity generating firms than generators.

In their 2017 reports the Australian Energy Market Operator (2017) and Australian Energy Market Commission (2017) provide evidence that the price spikes that are expected to occur as a result of the bidding and settlement structure outlined in this paper are present, see particularly the text from page 29 onwards in Australian Energy Market Commission (2017). These data provide evidence on the non-random nature of price spikes, and their excess occurrence in the first five-minutes of the settlement period. ${ }^{40}$ AEMC, however, have not yet provided evidence concerning the behavior of individual generators, or the extent of capacity being moved between price bands to achieve these outcomes.

AEMO provide extensive public data on rebidding on their website. Unfortunately, it is neither particularly transparent nor easy to use or manipulate. ${ }^{41}$ Drawing on the datasets available from AEMO we have isolated the rebidding behaviour of each generator in the NEM for the period $01 / 09 / 2015$ to $31 / 03 / 2017$ to obtain a picture of the differing activities available.

It is fair to say that the variety of strategies employed is remarkable, no doubt contributing to the difficulties in pinning down these behaviours at an industry level. However, it is also true that evidence of strategic behaviour in the form of rebidding occurs across all States and forms of power generation. For some generators the evidence occurs only rarely, sometimes associated with periods of market stress. In other generators the behaviour is evident for sustained periods of time and occurs multiple times in the same day.

We isolate rebidding from the dataset by finding changes in the quantity offered at the price bands in effect for each generator on that day. To simplify the problem slightly we concentrate only on rebids which occur for dispatch on the same day as the rebid (because of the structure of the bidding it is possible to rebid for a dispatch period on a different date). This leaves us with the possibility of rebidding for 48 possible dispatch periods in each day. The rebids can occur at any time of day, and we specifically focus on those which change the volume for immediate dispatch periods up to the end of the following settlement period (that is from the point of rebid until the end of the next 30 minute settlement period). The structure of the rebidding

\footnotetext{
${ }^{40}$ From July 2016 a stricter criteria against late-rebidding, within 15 minutes of dispatch, tended to push price spikes even more towards the first 5-minute period.

${ }^{41}$ The issues are somewhat parallel to the difficulties encountered in the transparency of high frequency financial market data in the 1990s, see Brandt and Kavajecz (2004).
} 
system is such that when a generator rebids, it rebids the volume for all half-hour periods of that day. That is, if we imagine the day as running from $t=0, \ldots, 48$, then regardless of when the rebid occurs, there may be volume changes recorded for all $t$, regardless of whether that period is in the past or not. This creates some particular difficulties in constructing the dataset, as clearly bids cannot be revised post-dispatch. This quirk of the dataset contributes greatly to the difficulty in assessing strategic changes in the supply schedule as past schedules need to be carefully constructed from an evolving dataset.

A convenient means of illustrating a rebid for a single point in time for a single generator is given in Figure 1. The top right hand panel represents the rebidding activity of a particular generator at 8:06:55 on May 24, 2016 (thus the heading for each panel is read as yyyymmddhhmmss). Along the right hand horizontal axis are the price bands ordered from lowest to highest. The left hand horizontal axis gives the dispatch period to which the supply bids apply. The vertical axis gives the quantity (in MW) of the change in volume offered by the generator in each of the bands pertaining to each dispatch period compared with the previously offered supply curve. That is, the charts show how the generator is realigning its volume up and down the supply curve at various points. Where the surface is flat there is no change in the supply of volume in that price band for this rebid. Valleys (or dips below zero) indicate volume is being removed from that price band, and hills (above zero) indicate volume being added to that price band. Note that in the vast majority of cases generators offer all their supply capacity at some price on the curve, and hence valleys and hills will generally net to zero as the volume is simply being shifted along the supply curve at each point in time. It is important to note that this three dimensional representation consists of a stack of supply curves which refer to individual points in time. As post-generation electricty is not currently storable in any meaningful way power is not being transferred from one dispatch period to the next by the actions of the generator.

The first point to note about the rebid given in the top left of Figure 1 is that it occurs at 8:06:55am. Consequently, all of the pre-8:06 changes in volume offered are irrelevant. That is most of the periods at the very front of the figure where volume is taken from the highest price band and moved to the lowest price band are simply irrelevant. The other dominant feature on the figure is the move of volume from a previously very low price band to the highest price bands - indicated by the red arrow. This rebid is taking volume from its previously lowest possible price band to the highest possible price band. In particular, this includes contributing to a steeper aggregate supply curve for the afternoon peak period from around $3 \mathrm{pm}-5 \mathrm{pm}$. The figure in the right hand top panel of Figure 1 shows the same generator rebidding again (its next rebid) later in the day at 15:13:03. It is apparent that now for the dispatch periods after 3:13pm volume is removed from the highest price bands to the lowest price bands. That is, compared with the original 'in good faith' bid by this generator volume was moved from the lowest to higher price bands at one point in the day, and then immediately prior to dispatch moved back from highest to lower price bands. Note that in the second rebid the same generator also moves volume for later in the evening from previously placed low price bands back to high price bands - perhaps in anticipation of the potential for later strategic plays. Because this generator is only one of a portfolio owned by the power generating company the strategic game is likely to be far more complex than the illustration from a single generator here as firms optimise across their suite of 
available generators.

A second example of rebidding behaviour is given in the lower panels of Figure 1. The lower left panel shows a bid on May 26, 2016 at 09:13:45am when volume is moved from the lowest to highest price bands as shown by the red arrow. A few minutes later, at 09:20:56am volume is moved back from the highest price band to the lowest for a subset of the original rebid.

While the individual generator stories are fascinating AEMO received between 6 and 8 million rebids annually between 2010 and 2015, making analysis of individual rebids infeasible. Table 1 provides descriptive statistics for rebids for eight sample generators across the period September 2015 to March 2017 by generator type and location; it includes generators of varying sizes from different States involved in NEM across a range of power generation types - coal, gas, hydro and wind including at least one representative of the dominant capacity production types (black and brown coal, gas, hydro, wind).

The generators do not all look the same (and it is worth noting that the price bands for each are not necessarily the same either across generator or across time). However, it is clear that each of the coal fired stations (GSTONE1, GSTONE6, LYA1) bid most of their volume in lowest price bands, bands 1 and 2, (recall that this is not the price they receive, it merely indicates that the costs of not dispatching are very high for coal fired stations). The fact that the highest median is in band 2, rather than band 1, reflects that band 1 is often placed at the allowed price floor of $\$ 1000$ per MWh, and reveals the skewness in the volume data. Coal fired stations also manage to allocate rather more to the highest price band on average than to bands 3 to 9 . And price band 10 has a relatively high standard deviation, which is unsurprising given that it incorporates the highest allowable price of $\$ 14,000$ per MWh. The two gas generators look quite different, AGLHAL has median volume concentrated at the top band and band 7, with a mean distribution which however reflects more volume dispatched towards the lower price bands. The difference between the mean and median volumes is prima facie evidence that there are some curiosities about the behaviour of these markets. PPCCGT, on the other hand, is primarily bidding volume in its lowest and highest price bands, reflected in both the mean and median results. The standard deviations are also highest in these bands. The two hydro stations are also quite different. Bastyan is a small generator and provides volume mainly at high price bands, while Tarraleah is a larger generator and tends to provide volume at its lowest price bands. Notably, however, the next highest standard deviations of these volumes are found in the higher price bands.

As discussed the diurnality and seasonality of rebids is a potentially difficult detail. Sun Metals (Sun Metals (2015a)) provided details of six particular instances when price spikes resulted from generators withholding volume. They claimed a lack of evidence of rebidding in the first 15 minutes of 30 minute dispatches and a preponderance of occurrences in the last 5 and 10 minutes. To provide some more background to this problem we provide a sample of the diurnal pattern of rebidding for GSTONE1 generator and AGLHAL in Figure 2 compiled by cumulating the number of rebids by 5-minute time interval over the day during the sample period. Prima facie there seems to be evidence of diurnal patterns, both within the day, where there is clearly more rebidding activity in and around the peak demand periods for power in the morning prior to 8 am and early evening. Additionally there are potentially hourly and/or half-hourly patterns 
consistent with the rebidding patterns proposed for the profit maximising firm by the theoretical framework.

To provide preliminary evidence that this is indeed the case we fit a sinusoidal curve of the form $x_{t}=A \cdot \sin (\omega * t+\phi)$ to each of the rebid counts of the form given in Figure 2 where $x_{t}$ represents the number of rebids in the 5-minute interval. The results where no-breaks are allowed within the day are remarkably consistent across different generators, giving statistically significant estimates of a cycle with a period of just over 15 minutes in each case. ${ }^{42}$ This is consistent with the idea that the generators may rebid more in the 10 minutes after the hour, and 10 minutes before the end of the half-hour than at other times. When we break the day into several sub-periods, from 4:00am to 10:000am (early morning), from 10:00am to 3:00am (peak work) and from 3:00pm to 10:00 (evening) we see that although the periodicity does not vary significantly, the amplitude of the cycle (that is the extent of rebidding) is substantially and significantly higher in the peak activity periods. These results are indicative that there is diurnality in the rebidding activity. Overall, the results support the claims by Sun Metals that there is more bidding in the late part of the half-hour dispatch period, but not clearly that there is none in the early part. However, the Sun Metals claim related specifically to rebidding related to price spikes. The relationship to price spikes by by generator and time of day is complex, and beyond the scope of this paper (it will be addressed in future research).

In an attempt to deal with some of the perceived strategic bidding behaviour, a 'late-bidding' rule was introduced to the market effective from July 1, 2016, midway through our sample period; AEMC (2015). This rule established that when a generator created a rebid during the last half of the relevant 30 minute dispatch period they could be required to provide detailed records of the reasons behind those bids, thus putting the onus of proving 'good faith' onto the generator. To demonstrate its effect we divide our sample period in halves, pre-July 2016 and post-July 2016. Figure 3 presents the proportion of bids which occur in the last 15 minutes of the half-hour intervals by a number of generators. It is clear that for the vast majority (Bastyan is the only exception) the proportion of rebidding activity meeting the late re-bidding category has dropped discernibly after the introduction of the rule. Our estimate here may be biased downwards, as the announcement of the new late rebidding requirements occurred in December 2015, and the market was aware that AEMC was examining this issue from at least mid-2015 when Sun Metals made submissions concerning this issue to both the AEMC and the Queensland Government (Sun Metals (2015b),Sun Metals (2015a)). It may also be notable that the absolute number of rebidding events has also dropped considerably for these generators across the two sample periods - although it is difficult to distinguish how much of this is due to changing underlying conditions or to the increased awareness of rebidding activity by regulators and analysts.

Finally, we provide evidence that the rebidding is not uniformly distributed across the price bands. In particular, for the eight generators shown in Table 1 we consider the extent to which rebidding events result in the removal of volume from/to the top two price bands to

\footnotetext{
${ }^{42}$ The period is given by $2 \pi / \omega$. The individual estimations are not presented in order to conserve space, and because while the cycle estimated is significant, the fit is poor and little is gained from the detailed results. A more sophisticated econometric approach is required to estimate the form of the diurnality properly, and is underway in future research. The preliminary results are available from the authors on request.
} 
the lowest two price bands and vice versa. This is the most likely evidence of volume changes for strategic reasons consistent with the modelling framework presented in this paper, as it represents substantial changes in volume available at either end of the supply curve, either for a strategic reason or as a result of extremely poor forecasting. Given the profitability of electricity generation in Australia in recent years the former seems a more likely explanation.

Table 2 gives three rows for each generator. These divide the total number of megawatts offered by the generator in their rebid actions and the volume which is shifted. The first row for each generator captures the vast majority of all rebid activity, where there is no change in the volume bid in that price band - consistent with the flat areas in Figure 1. In all cases over 85 percent of the generating volume offered does not change price band during the rebid. The second and third row indicate how much generation capacity is moved from one end of the supply curve to the other in the rebids. It is clear, from simply adding up all the shifted capacity in these three categories that there is almost no rebidding which lies out side these groups - all of the totals add up to 98 percent or greater of rebids. This means there are disproportionately large shifts in volume occurring between the lowest and highest price bands, consistent with strategic bidding activity. The wind generator, HALLWF2 shows least evidence of this, which is consistent with wind being a non-synchronised, non-baseload generation source. The largest proportions of capacity offered shifting between the two tails occur for the coal stations in Queensland, consistent with the literature presented in Section 2.2 outlining the evidence for price manipulation in that State.

\section{Conclusion}

Electricity generation supply systems around the globe have attempted to solve the problem of determining competitive prices for power when faced with oligopolistic suppliers. Theoretical frameworks have been developed to capture the salient features of these markets, but one potentially important feature has thus far been neglected. Many of the existing systems allow for electricity generators to rebid their original offers to supply in the lead-up to the actual dispatch. While pragmatically this has been an acceptable solution to the problem of relatively infrequent observations on electricity demand, it has previously been unclear to what extent it may facilitate strategic supply curve behaviour on the behalf of the generators.

This paper has developed a theoretical framework to incorporate rebidding behaviour into our understanding of the provision of supply by electricity generators and its potential to influence price volatility and levels at wholesale level. Both higher wholesale prices and volatility are passed to retail consumers in the form of higher prices. Using data for the Australian NEM we have for the first time, to our knowledge, provided evidence of strategic behaviour across the supply curve by individual generators which shows the potential of supply curve strategies which impact prices in precisely the way predicted by our theoretical model. Only recently has empirical evidence on this behaviour begun to emerge, at least partly due to the complexity of the datasets and a need to utilise big data techniques to control for diurnality, seasonality and other non-annual patterns in extracting the summary statistics to describe the observed outcomes. Future work will aim to quantify the extent to which portfolios of generators could result in more nuanced strategic behaviours than revealed here via individual generators. However, the fact that we can detect 
strategic supply curve behaviour in individual generators, across alternative power generating sources and geographic locations in the NEM provides ample support of the incentives created by the market design to create profitable opportunities. The problems inherent in this market draw attention to the importance of market design and implementation when trading off the pragmatic need for technical solutions detailed in Australian Energy Market Operator (2017) with the incentives faced by firms generating financial profits. 


\section{References}

Australian Energy Market Commission. 2015. Final Rule Determination National Electricity Amendment (Bidding in Good Faith). Tech. rept. December.

Australian Energy Market Commission. 2017. Draft Rule Determination National Electricity Amendment ( Five Minute Settlement) Rule 201\%. Tech. rept. September.

Australian Energy Market Operator. 2017. Five-minute settlement: High level design to support AEMC Draft.

Australian Energy Regulator. 2015. State of the Energy Market. 1-149.

Bolle, Friedel. 1992. Supply function equilibria and the danger of tacit collusion. The case of spot markets for electricity. Energy Economics, 14(2), 94-102.

Borenstein, Severin, Bushnell, James B, and Wolak, Frank A. 2002. Measuring market inefficiencies in California's restructured wholesale electricity market. The American Economic Review, 92(5), 1376-1405.

Brandt, Michael W, and Kavajecz, Kenneth A. 2004. Price discovery in the US Treasury market: The impact of orderflow and liquidity on the yield curve. The Journal of Finance, 59(6), 26232654 .

Chester, Lynne. 2006. The conundrums facing Australia's national electricity market. Economic Papers, 25(4), 362-377.

Clements, A.E., Hurn, A.S., and Li, Z. 2016. Strategic bidding and rebidding in electricity markets. Energy Economics, 59, 24-36.

Fabra, Natalia, Fehr, Nils-Henrik, and Harbord, David. 2006. Designing electricity auctions. The RAND Journal of Economics, 37(1), 23-46.

Green, Richard J, and Newbery, David M. 1992. Competition in the British electricity spot market. Journal of political economy, 100(5), 929-953.

Handika, Rangga, Truong, Chi, Trueck, Stefan, Weron, Rafal, et al. 2014. Modelling price spikes in electricity markets-the impact of load, weather and capacity. Tech. rept. Hugo Steinhaus Center, Wroclaw University of Technology.

Hortaçsu, Ali, and Puller, Steven L. 2008. Understanding strategic bidding in multi-unit auctions: A case study and rebidding in electricity markets. RAND Journal of Economics, 39(1), $86-114$.

Hurn, A Stan, Silvennoinen, Annastiina, and Teräsvirta, Timo. 2016. A smooth transition logit model of the effects of deregulation in the electricity market. Journal of Applied Econometrics, 31(4), 707-733.

Kastl, J. 2011. Discrete bids and empirical inference in divisible good auctions. The Review of Economic Studies, 78, 974-1014. 
Klemperer, Paul D, and Meyer, Margaret A. 1989. Supply function equilibria in oligopoly under uncertainty. Econometrica: Journal of the Econometric Society, 1243-1277.

McAfee, R Preston, and McMillan, John. 1987. Auctions and bidding. Journal of Economic Literature, 25(2), 699-738.

Moldovanu, Benny, and Tietzel, Manfred. 1998. Goethe's second-price auction. Journal of Political Economy, 106(4), 854-859.

Newbery, David M. 1998. Competition, Contracts, and Entry in the Electricity Spot Market. The RAND Journal of Economics, 29(4), 726-749.

Sun Metals. 2015a. Response to Issues Paper on Electricity Pricing in Queensland released in October 2015. Tech. rept. November.

Sun Metals. 2015b. Response to Issues Paper on Electricity Pricing in Queensland released in October 2015. Tech. rept. November.

Sweeting, Andrew. 2007. Market power in the England And Wales wholesale electricity market 1995-2000. Economic Journal, 117(520), 654-685.

von der Fehr, N, and Harbord, D. 1993. Spot Market Competition in the UK Electricity Industry. The Economic Journal, 103, 531-546.

Wilson, R. 1979. Auctions of shares. Quarterly Journal of Economics, 93, 678-691.

Wilson, R. 2002. Architecture of Power Markets. Econometrica, 70, 1299-1340.

Wolak, Frank A. 2000. Market Design and Price Behavior in Restructured Electricity Markets: An International Comparison. Vol. 8. 

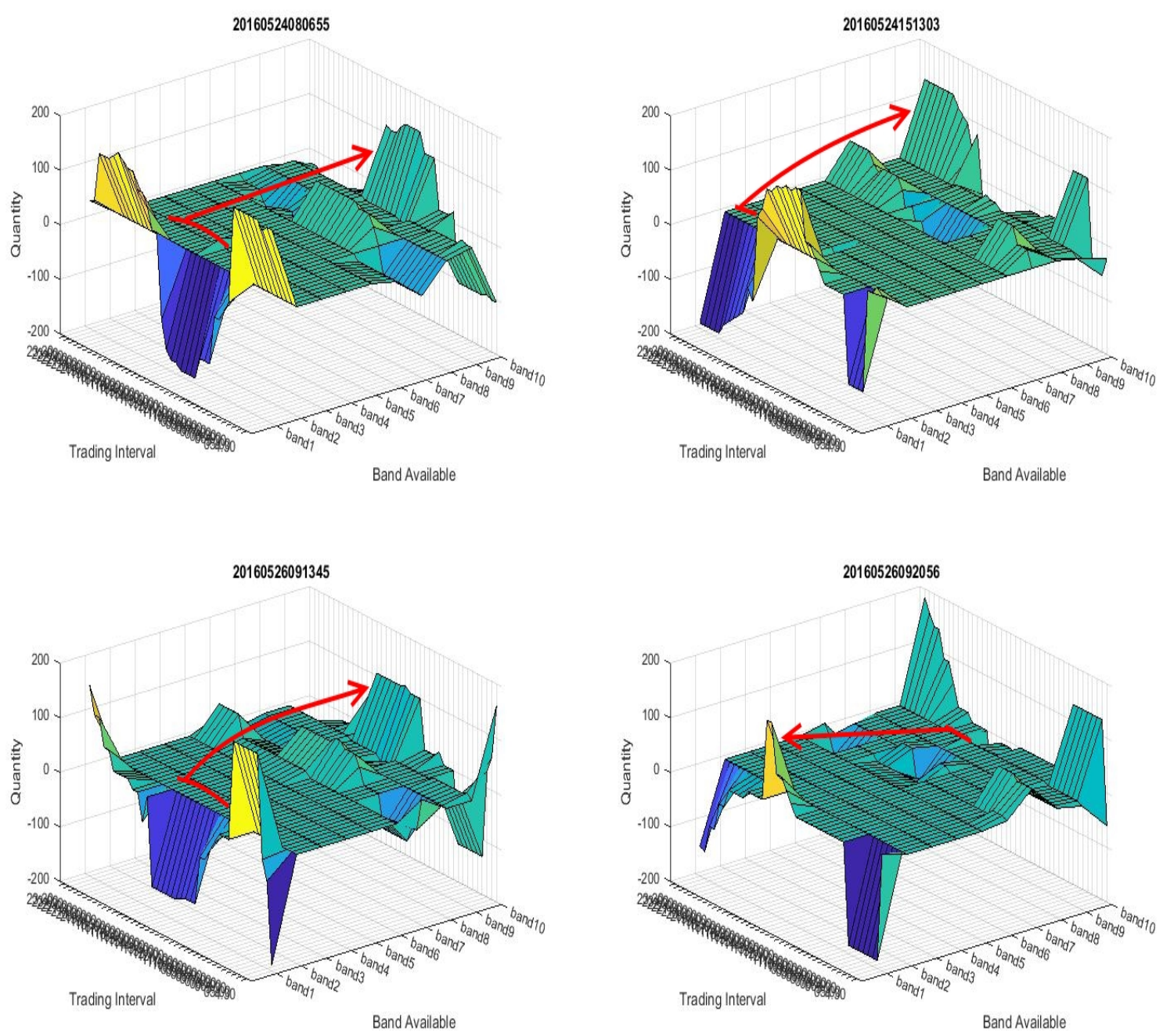

Figure 1: Changes in volume via rebid for a specific generator. The title for each panel is in the form YYYYMMDDHHMMSS, the upper panels present two consecutive rebids on May 24, 2016 and the lower panels two consecutive rebids on May 26, 2016. The right horizontal axis on each figure represents ascending price bands and the left horizontal axes gives the trading interval with the earliest towards the front of the figure. The vertical axis gives the change in volume. The arrows show the direction of shifts between band 1 and band 10 . 

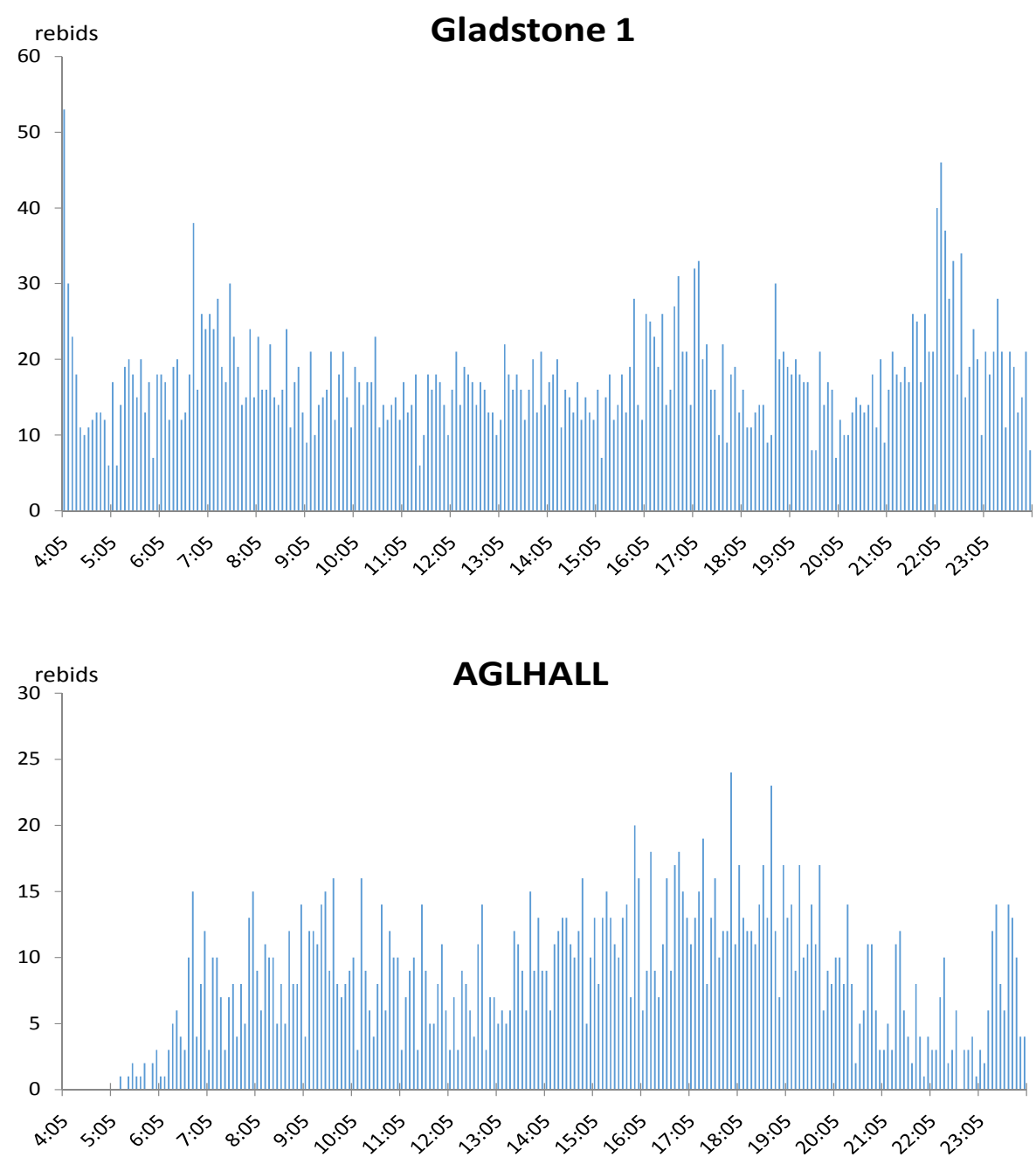

Figure 2: Rebidding activity by number of rebids in a 5-minute period over a day for 2015-2016 by generator 


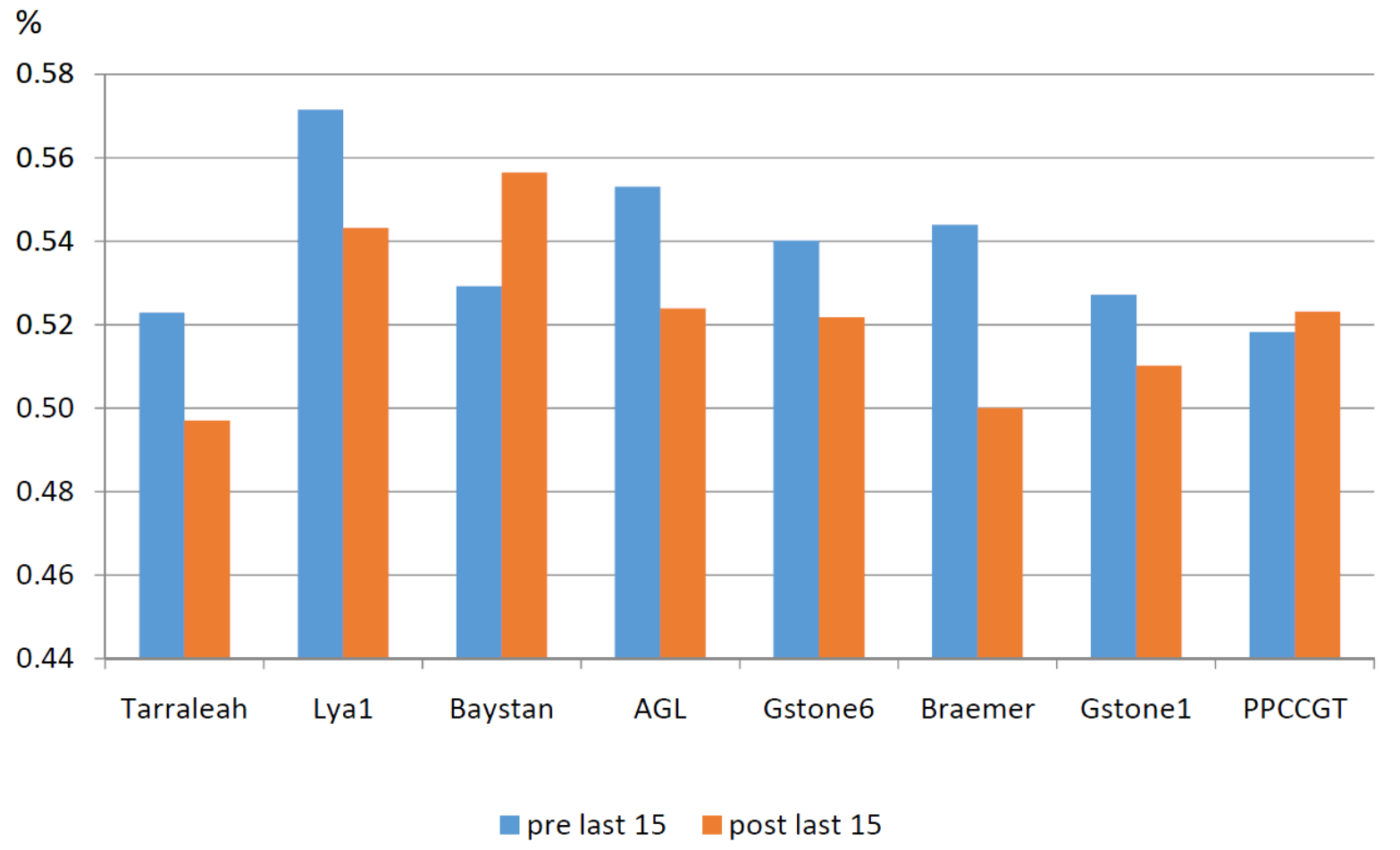

Figure 3: Proportion of rebidding activity taking place in the first 15 minutes of each half-hour pre the implementation of late-bidding rules and post the change to late-bidding rules 


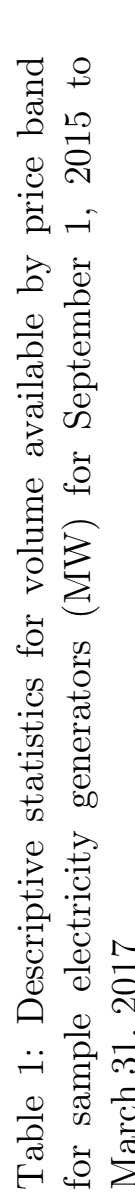

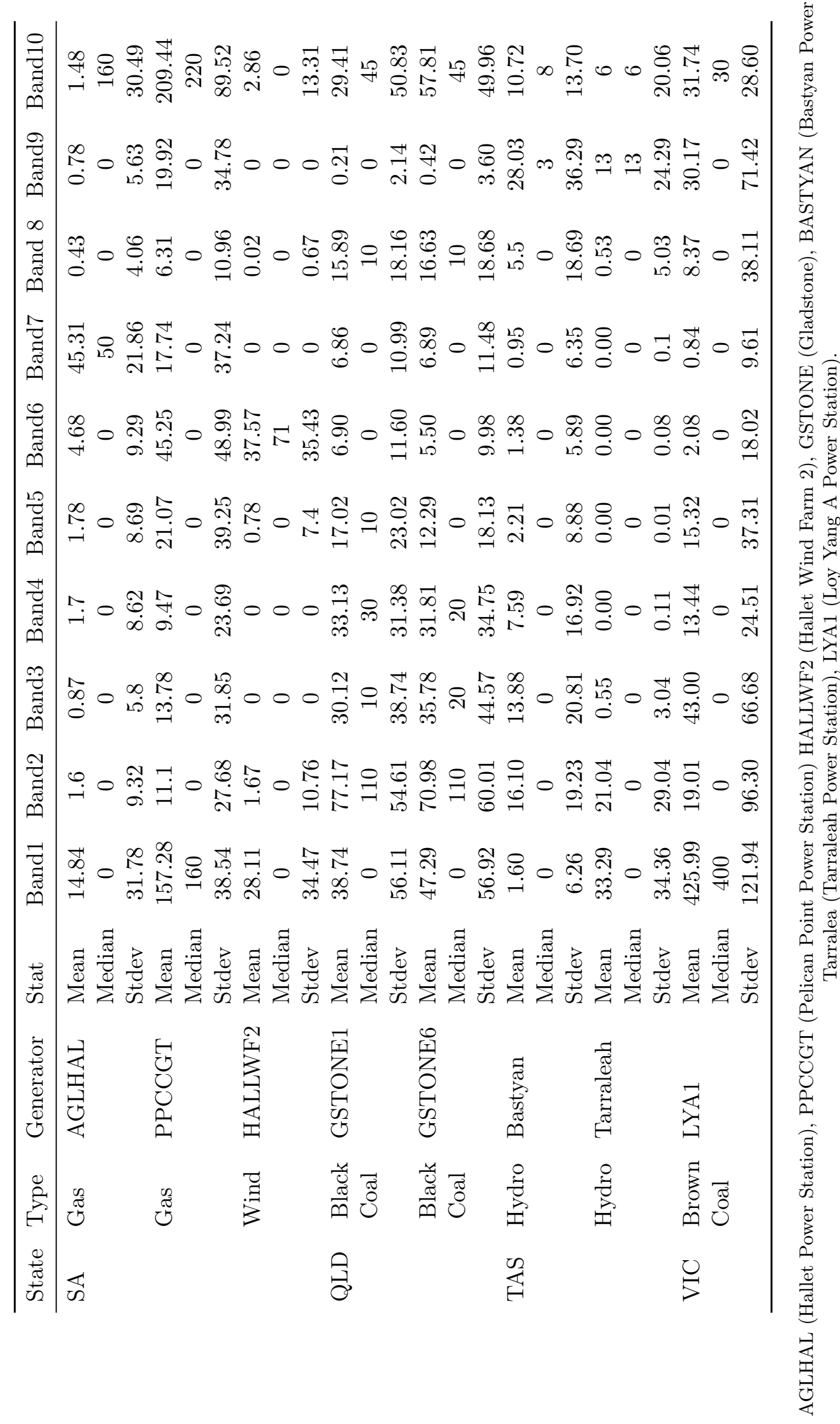


Table 2: Proportion of volume (MW) shifted in rebids between bands, September 1, 2015 to March 31, 2017

\begin{tabular}{|c|c|c|c|c|c|}
\hline State & Type & Generator & & Volume shifted & Percent of total \\
\hline \multirow[t]{9}{*}{$\mathrm{SA}$} & Gas & AGLHAL & No Shift & 70998 & 89 \\
\hline & & & Shift from Bands 9-10 to Bands 1-2 & 2464 & 3 \\
\hline & & & Shift from Bands 1-2 to Bands 9-10 & 5902 & 7 \\
\hline & Gas & PPCCGT & No Shift & 79364 & 92 \\
\hline & & & Shift from Bands 9-10 to Bands 1-2 & 1747 & 2 \\
\hline & & & Shift from Bands 1-2 to Bands 9-10 & 3029 & 4 \\
\hline & Wind & HALLWF2 & No Shift & 1894 & 99 \\
\hline & & & Shift from Bands 9-10 to Bands 1-2 & 8 & 0.5 \\
\hline & & & Shift from Bands 1-2 to Bands 9-10 & 8 & 0.5 \\
\hline \multirow[t]{6}{*}{ QLD } & Black & GSTONE1 & No Shift & 150366 & 87 \\
\hline & coal & & Shift from Bands 9-10 to Bands 1-2 & 8999 & 5 \\
\hline & & & Shift from Bands 1-2 to Bands 9-10 & 12273 & 7 \\
\hline & Black & GSTONE6 & No Shift & 138112 & 87 \\
\hline & coal & & Shift from Bands 9-10 to Bands 1-2 & 8319 & 5 \\
\hline & & & Shift from Bands 1-2 to Bands 9-10 & 11635 & 7 \\
\hline \multirow[t]{6}{*}{ TAS } & Hydro & Bastyan & No Shift & 49478 & 93 \\
\hline & & & Shift from Bands 9-10 to Bands 1-2 & 1543 & 3 \\
\hline & & & Shift from Bands 1-2 to Bands 9-10 & 1823 & 4 \\
\hline & Hydro & Tarralea & No Shift & 24548 & 96 \\
\hline & & & Shift from Bands 9-10 to Bands 1-2 & 243 & 1 \\
\hline & & & Shift from Bands 1-2 to Bands 9-10 & 636 & 3 \\
\hline \multirow[t]{3}{*}{ VIC } & Brown & LYA1 & No Shift & 89219 & 96 \\
\hline & coal & & Shift from Bands 9-10 to Bands 1-2 & 1483 & 2 \\
\hline & & & Shift from Bands 1-2 to Bands 9-10 & 2078 & 1 \\
\hline
\end{tabular}

AGLHAL (Hallet Power Station), PPCCGT (Pelican Point Power Station) HALLWF2 (Hallet Wind Farm 2), GSTONE (Gladstone), BASTYAN (Bastyan Power Station), Tarralea (Tarraleah Power Station), LYA1 (Loy Yang A Power Station). 


\section{APPENDIX}

\section{APPENDIX: SYMMETRIC SFES}

Suppose there are two firms, $i$ and $j$. The cost of producing $q_{i}$ is $C_{i}\left(q_{i}\right)$, a convex function, with $C_{i}^{\prime} \geq 0$. Assume firm $j$ 's supply function is $S_{i}(p)$. Then firm $i$ 's residual demand function is

$$
R_{i}(p, a)=D(p, a)-S_{j}(p)
$$

Firm $i$ 's equilibrium output in state $a$ must satisfy the residual demand, i.e..

$$
q_{i}(a)=D(p, a)-S_{j}(p)
$$

Firm $i$ 's profit function in state $a$ is

$$
\Pi_{i}(p, a) \equiv p \times R_{i}(p, a)-C_{i}\left[R_{i}(p, a)\right]
$$

In state $a$, given the rival's supply function $S_{j}(p)$, firm $i$ would like to choose a $p$ that maximizes its profit. The FOC for firm $i$ is

$$
R_{i}(p, a)+p \frac{\partial R_{i}(p, a)}{\partial p}-C_{i}^{\prime}\left[R_{i}(p, a)\right] \frac{\partial R_{i}(p, a)}{\partial p}=0
$$

This eq can be re-written as

$$
D(p, a)-S_{j}(p)=-\left[p-C_{i}^{\prime}\left(q_{i}\right)\right]\left[\frac{\partial D(p, a)}{\partial p}-S_{j}^{\prime}(p)\right]
$$

Using the market clearing condition $q_{i}=D(p, a)-S_{j}(p)$, firm $i$ 's optimality condition (A.1) becomes

$$
\frac{q_{i}}{\left[p-C_{i}^{\prime}\left(q_{i}\right)\right]}=S_{j}^{\prime}(p)-\frac{\partial D(p, a)}{\partial p}
$$

Similarly, given firm $i$ 's supply function $S_{i}(p)$, firm $j$ 's optimality condition is

$$
\frac{q_{j}}{\left[p-C_{j}^{\prime}\left(q_{j}\right)\right]}=S_{i}^{\prime}(p)-\frac{\partial D(p, a)}{\partial p}
$$

Solving the pair of differential equations (A.2) and (A.3), one obtain a SFE. Consider the case where both firms have the same cost function. Then we seek a symmetric SFE where both firms bid identical supply functions $q=q(p)$. We thus face only a single differential equation

$$
\frac{d q}{d p}=\frac{q}{p-C^{\prime}(q)}+D_{p}
$$

If $C^{\prime}(q)=\gamma q, \gamma>0$, and $D_{p}=-b<0$, this equation can be solved analytically, yielding a unique SFE, provided that we insists that all $p \in[0, \infty)$ are possible; see Klemperer and Mayer, p. 1260.

Remark: In the main text, we showed that if firm $j$ 's supply function in $S_{j}(p)=\beta p$, then firm $\imath$ 's best response is

$$
q_{i}(p)=\frac{(b+\beta)}{1+\gamma_{i}(b+\beta)} p \equiv \omega p
$$


If the two firms have identical cost functions, i.e. $\gamma_{i}=\gamma_{j}=\gamma>0$, then in a symmetric equilibrium, we must have $\omega=\beta$. Thus we can solve for $\omega$ from

$$
\frac{(b+\omega)}{1+\gamma(b+\omega)}=\omega(\gamma \neq 0)
$$

Then $^{43}$

$$
\omega^{2}+b \omega-(b / \gamma)=0
$$

Choosing the positive root (because we require an upward-sloping supply function), we obtain

$$
\omega=\frac{1}{2}\left[-b+\sqrt{b^{2}+\frac{4 b}{\gamma}}\right]
$$

which is the same as in Klemperer and Meyer (1989, p. 1261).

\footnotetext{
${ }^{43}$ If $\gamma=0$, then above equation has no solution for $b \neq 0$.
} 